\section{The Making of an Epoch-Making Anime \\ Understanding the Landmark Status of Neon Genesis Evangelion in Otaku Culture}

\author{
Zoltan Kacsuk
}

I995 was a year of shocks for Japan. The Great Hanshin earthquake destroyed and damaged large portions of Kobe and its surroundings in January, resulting in the largest-scale destruction by an earthquake in Japan since the Great Kantō earthquake in 1923. Next, the Aum Shinrikyō sect committed an unprecedented act of terrorism, an orchestrated sarin gas attack in the Tokyo subway system in March. The general mood engendered by these events was further exacerbated by the growing sense of realization that the boom of the bubble economy that had burst at the end of the I980s was not returning, and the economic stagnation that followed in its wake was the new norm (Maejima 20I0; Uno 2008). The uneasiness felt at the time contributed to pop psychology and words like 'trauma' and 'adult children' becoming prevalent in popular discourse, leading to an increased interest in the inner-self and self-reflection (Maejima 2010: 32).

It was with this general social backdrop that Neon Genesis Evangelion (EVA) started airing in the fall of I995. After a low-key reception with a small core audience on its initial broadcast, the series grew exponentially into what is commonly referred to as a social phenomenon (or EVA shock) during its first re-airing in I997 and then leading into the theatrical release of both Neon Genesis Evangelion: Death o Rebirth and The End of Evangelion in the same year. This phenomenal popularity seems to indicate that EVA did indeed manage to capture the zeitgeist in a unique way (cf. Uno 2008), and resonated
How to cite this book chapter: Kacsuk, Z. 202I. The Making of an Epoch-Making Anime: Understanding the Landmark Status of Neon Genesis Evangelion in Otaku Culture. In: Santiago Iglesias, J. A. and Soler Baena, A. (Eds.). Anime Studies: Media-Specific Approaches to Neon Genesis Evangelion. Pp. 2I 5-246 Stockholm: Stockholm University Press. DOI: https://doi.org /IO.I6993/bbp.h. License: CC-BY 4.0 
I. The closest translation of otaku would be geek in English. For a discussion of the meaning of the term, see the next section. In Japanese, otaku is written in various forms (hiragana, katakana and Latin script) to connote different positions regarding its implied meanings. For my present analysis, these nuances are secondary and I therefore quote all instances of otaku in this single, simple form. For a discussion of the connotations of the various forms in Japanese, see, for example, Galbraith, Kam \& Kamm (2015) or Yoshimoto (2009).

2. Although Morikawa does not directly attribute the transformation of Akihabara from electric town-with a large concentration of shops dealing in electronic devices-to otaku town to the success of $E V A$, he does list a number of pieces of evidence that seem to suggest a strong link, and he offers a detailed interview excerpt as an illustration of this being the actual case for at least one of the pioneering shops to make the move (2003: 56-62). Before, EVA figurine shops were mostly located in Tokyo neighborhoods where young people would gather, such as Kichijōji or Shibuya. But the capital injection provided by the sudden increase in demand-engendered by the EVA boom-for custom hobby model kits led to said shop relocating to Akihabara, purely based on the notion that most of their clientele would go there for electronics supplies anyway. The success enjoyed by the first pioneers quickly led to an exodus of small and larger retailers all relocating to or opening branches in Akihabara. This account of Akihabara's transformation from Morikawa's book is also available in English (201 2 [2003]). with an audience beyond its original target audience of otaku. ${ }^{1}$ This widespread success led to a re-evaluation of the then denigrated figure of the otaku, and the sheer commercial force of the otaku market could no longer be ignored (Lamarre 2009: I 53), as also evidenced by the rapid transformation of Tokyo's Akihabara, with an unprecedented concentration of shops catering to otaku interests, which opened up in the neighborhood within the span of a couple of years after the EVA boom (Morikawa 2003). ${ }^{2}$ The anime industry was also changed by the series' and the subsequent movies' impact, leading to what is commonly understood to be the third anime boom, "facilitating the creation of the new time-slot and category of 'late-night anime" "and "propagating the production committee model of anime production due to its successes" (Suan 201 8: 204).

It is easy to assume that the above-outlined economic impact of the series and its influence on anime production and distribution practices is responsible for how it has come to be considered an epoch-making anime. Although these facets of its impact are undeniably a part of the equation, I would like to suggest that there is a more fundamental level on which EVA has proven to be epoch-making, and it is this deeper level that is in part responsible for the perceived naturalization of the economic and business arguments. The reason I refer to the economic and business arguments as less fundamental is because the significance of these types of changes can be reinterpreted according to the relative symbolic weight carried by the works under discussion, as we will see in the case of anime booms below. Few are the cases like that of Astro Boy, where a given work is undeniably the source of the economic and business effects associated with it. Thus, examining the arguments and positions in relation to this more fundamental level will be the focus of the present chapter.

From a perspective informed by the sociology of art, great works of art-or in our case epoch-making ones-are created neither by a genius author nor by a team, but rather, as Becker (I982), Bourdieu (I996 
[1992]) and Williams (I980 [I96I]) all point out with differing vocabularies, they are the products of much larger systems of production and dissemination, of popular and critical reception, of consecrating institutions, of scholarly and archival work, and of latter works that consciously or unknowingly engage with them. The way in which great works are selected and consecrated operates along very similar logics in the subfields of cultural production further away from the already legitimized arts—-to use Bourdieu's vocabulary-as Beaty and Woo (20I6) demonstrate in relation to comic books.

It is in this vein that I turn to the Japanese critical discourse to make sense of how EVA has come to be constructed as an epochmaking great work of anime there. Although this is not the only arena in which such construction takes place, it is definitely an important one. By critical discourse, I refer to a particular domain of mostly written intellectual exchange in Japanese, which comprises a range of publications that are not necessarily rigorously academic: Indeed, they are often written with a more general audience in mind, but they are nevertheless invested in moving forward the discussion around their topics of interest as opposed to a simple popularization of works or concepts. This discursive space borders on and overlaps with the domain of academic research in one direction, on art/literary/cultural criticism in another, and finally on popular science and public intellectual discourse along a third angle. Its contributors thus come from various backgrounds ranging from the humanities (e.g., Hiroki Azuma), psychology (e.g., Tamaki Saitō) and social sciences (e.g., Kaichirō Morikawa), to critics writing on popular media (e.g., Gō Itō, ${ }^{3}$ Satoshi Maejima, Tsunehiro Uno, Taimatsu Yoshimoto), journalists, editors and even creators themselves (e.g., Eiji Ōtsuka, Toshio Okada). Despite its breadth and variety in positions, the discourse nevertheless provides a semi-coherent space, which is not only evidenced by the way these authors build on one another's ideas, but also in the way they are regularly featured in conversation with or alongside one 
another in publications. This unique space of intellectual exchange has been highly productive in relation to new approaches and concepts for engaging with anime, manga, light novels, video games, otaku and related domains, some of which will be discussed in the following; and which, in general, as I have argued elsewhere, can significantly further the theoretical work being undertaken, for example, in Anglophone Fan Studies, Comics Studies and beyond (Kacsuk 2016a).

The status of EVA as a landmark work in the Japanese critical discourse is aptly demonstrated by the way it is either seen as (I) a culmination or end point, (2) an origin point or (3) as the single best representative of a larger phenomenon or paradigm shift. For example, in relation to (I), Ötsuka (2004) concludes that EVA is the ultimate attempt at addressing "Astro Boy's dilemma" (Atomu no meidai), and for Uno (2018) it is the "final accounts" of the robot anime genre. As (2) an origin point, for instance, EVA is not only the fountainhead of a major anime boom and potentially responsible for sparking the transformation of Akihabara, but is also understood to be one of the major inspirations for the sekaikeit mode/genre, and the source of its original conceptualization (Maejima 20I0). Finally, with reference to (3), for Uno (2008), EVA embodies the imagination of mid-I990s Japanese popular culture, and for Azuma (2009 [first edition: 200I]) and Maejima (2010), EVA marks a number of important shifts in otaku culture, discussed in detail later.

Tracing the various arguments in the Japanese critical discourse that position EVA as a landmark work, two things become very obvious straightaway. First, it is an unquestionable consensus that EVA was a watershed phenomenon. Even authors like Ōtsuka (2004), who vocally disliked the series initially, or Uno (2018), who has been one of the strongest voices in providing a counter-reading to the significance of post-EVA works and thereby to the significance of $E V A$

4. See below for a detailed discussion of the term's meaning. itself (2008), have found approaches to re-evaluate it in a way that conforms to this idea, as explained later. Second, although there are 
arguments that underline the impact of EVA in relation to anime or Japanese society at large, the majority of the points raised center on the series' relationship with otaku culture. This points toward another, more fundamental aspect of EVA's position in the Japanese critical discourse, one that only becomes apparent when considering the shifts in this discursive space over time. As a result of EVA's impact on it, EVA's landmark status and the meaning of otaku culture have inextricably become constituted together.

The way otaku culture and the significance of EVA are constituted together is precisely why EVA can be considered an epochmaking work: it has engendered an intervention in the discourse around otaku culture that has effected lasting discursive changes. The very content of the term otaku has been warped by EVA, or more precisely, the changes in the meaning of the term have been determined by the position of EVA in the critical discourse. It is not just one term, however, it is a host of terms and concepts that have been mobilized and reconfigured, most notably 'anime boom,' 'otaku generations' and 'sekaikei.'

In order to demonstrate this interrelation between the meaning of otaku culture and EVA's consistent positioning as a landmark work within the Japanese critical discourse, I will proceed by first providing a short introduction to the complexity of defining otaku culture, followed by a look at the significance of anime for otaku culture. I will then turn to discussing the concepts of anime boom, otaku generation and sekaikei and how they attest to EVA's impact on conceptualizing otaku culture. Finally, in the last two sections of this chapter I will, on the one hand, offer further potential ways to see the interrelation between the significance of EVA and the meaning of otaku culture; and, on the other, I will highlight the force exerted by the consensus regarding EVA's landmark position even on authors who have demonstrated a critical stance in relation to the show and its reception.
5. These interlinked shifts in meaning are not unlike the ones highlighted in Williams (1979 [1976]), albeit on a far more compact timeline and a much smaller scale. 


\section{Otaku and Otaku Culture}

Otaku culture, like any (sub)cultural formation, is very tricky to pin down. On the one hand, otaku culture only exists on the level of discourse, be it theoretical or popular. ${ }^{6}$ It is a concept created to refer to a set of phenomena, far from being cohesive and well-delineated. Indeed, if we were to shift our emphases and groupings along different lines, we would end up with a very different version of what otaku culture means. This, in fact, is one crucial topic of this chapter. As Aida notes, "discourses on "otaku" . . a and "actual otaku" must be strictly distinguished' (2015: I05). On the other hand, however, as this distinction itself implies, there are people who explicitly or implicitly identify with the term (however varying the meaning); there are shops, products and media that supposedly cater to an otaku clientele, and there are conventions and other types of meetings where people come together to engage in activities commonly associated with otaku. This, then, is the double bind of discussing social and cultural formations: there are categories that exist on the level of theory and discourse, and then there are myriad forms of action, tastes, artifacts, modes of engagement and belonging, which do seem to demonstrate patterns of affinity, but never equal the concept. As Alfred Korzybski put it so well, the "map is not the territory it represents, but, if correct, it has a similar structure to the territory' (I996 [1933]: 58, emphases in the original). Various solutions to this problem have been put forward, for example, by Azuma (2009 [200I]), Morikawa (2003), Yoshimoto (2009), Galbraith, Kam and Kamm (20I 5) and Kacsuk (20I6b). In this chapter, however, I only highlight two aspects of the discussions on otaku culture. First, in relation to the popular discourse, I will offer an ever-so-brief history of the term itself in Japan. Second, to reference the just as compli-

6. For a very thorough summary of the various approaches to otaku and otaku culture in the Japanese scholarly and critical discourse, see Aida (20I 5 ). cated level of actual social interactions and tastes, I will highlight the way in which otaku practices and interests are addressed in the Japanese critical discourse. 
The term otaku was supposedly first used by SF fans from Keiō University Tokyo, some of whom went on to create the TV anime Super Dimension Fortress Macross (1982-83), which featured the term in dialogue. It was then appropriated by a wider strata of fans and taken up as a derogatory term within the fandom itself (Okada I996: 8-9). This phase of the term's history is followed by its endlessly retold appearance in the magazine Manga Burikko in the provocative four-part series Otaku no kenkyū (Otaku research) written by Akio Nakamori (with the last piece authored by Sonta Eji) and starting in 1983 (for discussions of the series see, e.g., Ōtsuka 2004; Yamanaka 20I 5; Yoshimoto 2009). Precisely because Manga Burikko was a niche medium (cf. Thornton I996 [I995]) of the culture itself, this exposure had an effect within the concerned fandoms, that is, an internal debate about the ethics of using the term to denigrate others. Yamanaka points out how the debate surrounding the article series led people to re-adopt the term otaku in self-mocking fashion (20I 5: 46-47), which is often the first step toward the reclamation of an identity. The next stage in the evolution of the term was the infamous Tsutomu Miyazaki serial murder case, which brought about both mainstream exposure of otaku and a moral panic (Ito 20I2: xxi; see also Kamm 20I5). The negative image was further reinforced by the March 1995 Sarin gas attack committed by members of Aum Shinrikyō in the Tokyo subway system, and the discussions that followed regarding whether Aum Shinrikyō had been an otaku sect. ${ }^{7}$ Finally, after a series of events, such as the publication of Okada's Otakugaku nyümon (Introduction to Otakuology, I996) and his public appearances and lecture series on otaku culture at the University of Tokyo, the generational mainstream success of EVA, and then almost a decade later the society-wide popularity of the media franchise Densha Otoko (Train Man), the term otaku came to be rehabilitated to mean people deeply engaged in very specific non-mainstream interests (see Kikuchi 20I 5; Ito 20I2).
7. Both Morikawa (2003) and Uno (2018) discuss the obvious anime influences on Aum Shinrikyō's propaganda and teachings. 
8. See Aida (2015) for an overview of a number of such definitions.

9. Meaning beautiful young girl, bishōjo is often used as an umbrella term for a family of character types heavily featured in many Japanese anime, manga and video games.

Io. Large (fighting) machines, often resembling a humanoid or bipedal form, commonly operated by a single pilot from a cockpit inside the mecha itself. See Chapter 6 by Manuel Hernández-Pérez.

I I. Namely "doujinshi, cosplay materials, trading cards, dolls, anime character goods, products related to manga-anime-games" (Morikawa 2003: 47).
Turning to the level of practice, the emergence of otaku culture can be seen as a result of the expansion and diffusion of SF culture around the late I970s and early I980s (Okada 2008; Yoshimoto 2009). Most of the implicit and explicit definitions of otaku culture in the Japanese critical discourse center on one or more of the following: (I) the level of content and media, or in other words, genres and formats characteristic of otaku culture; (2) the different interest communities or fandoms; and (3) the specific mode of engagement.

There is a further group of definitions, which I deliberately omitted from this list and which will not be discussed here, as they are more focused on otaku personality traits-often framed as pathologies-rather than otaku culture as a cultural formation, such as Saitō's famous characterization that otaku are distinguished by their sexual interest being focused on two dimensional characters (20II [2000]). ${ }^{8}$

Enumerations of the interests within otaku culture (e.g., Azuma 2009 [200I]; Morikawa 2003; Okada 2008; Yoshimoto 2009) are strikingly similar, with SF, fantasy, games, manga, anime and idol culture acting as central nodes for most of them. For Morikawa, the "structure of interest"- the affinity between technology such as personal computers and laser discs on the one hand, and anime, video games, fan-made manga, custom hobby model kits, etc. on the other (2003: 63)-ultimately defines what otaku are (2003: 268). In a similar fashion, Yoshimoto's "otaku genre" is characterized by the presence of "bishōjo ${ }^{9}$, mecha ${ }^{10}$ and further SF elements, magic and other fantasy elements, sexual and romantic elements," and otaku are defined as males who enjoy works that belong to the "otaku genre" and who self-identify as otaku (2009: 8). Although the elements of these two enumerations are different insofar as Morikawa focuses on various media and product types, ${ }^{11}$ whereas Yoshimoto concentrates on various traits of genre fiction, they actually complement each other to provide a general picture of the range of otaku interests. 
Okada (2008) and Yoshimoto (2009) also enumerate a series of interrelated fandoms that belong to (the larger) otaku culture, such as military fans, railway fans, SF fans, anime fans, manga fans, special effects fans, kaiju fans, ${ }^{12}$ etc. Again, some of these fandoms seem to be defined along the lines of media form, while others are organized around content and genre. For Okada, however, otaku culture differs from specific fandoms such as those invested in SF, anime, kaijū or manga, in the way in which it operates on a level that requires a nuanced understanding of the canons and conventions of all these areas (1996: 28). ${ }^{13}$ There is a sense of the coming together of elements from various genres and media in all of these definitions. But while Okada locates otaku culture in the mode of engagement, Yoshimoto assumes the crystallization of a whole new genre on the level of works. ${ }^{14}$ This is probably the reason why Yoshimoto sees a direct continuity with the emergence of $m o e^{15}$ works, whereas Okada positions moe-focused consumption in opposition to the "true mode of otaku appreciation," a point to which I will return later.

\section{The Significance of Anime for Otaku Culture}

For overseas fans of otaku culture, the primacy of anime is an unquestionable fact, especially from a historical perspective, with anime having been the most important entry point and catalyst for the growth of anime-manga fandom in many countries (see, e.g., Eng 20I2; Kacsuk 2016b; Leonard 2005; Malone 20I0; Pellitteri 20I0). Anime, however, is just as central to otaku culture in Japan. The general understanding within the Japanese critical discourse is that otaku culture crystallized in the late I970s and early I980s when anime for a teenage to young adult audience emerged, spearheaded by Space Battleship Yamato (1974-75) and Mobile Suit Gundam (1979-80).

Although the previous section's enumerations may suggest that anime is just one among many interests in the mix that constitutes
I2. Kaiju (monster) refers to both the genre of Japanese movies featuring monsters and the creatures themselves, most famously Godzilla. A closely related genre label is that of special effects (tokusatsu) movies and TV shows, which often also feature monsters and/or superheroes.

I3. Although there is a strong continuity between Okada's positions in Otakugaku nyümon (I996) and Otaku wa sude ni shinde iru (Otaku are already dead) (2008), there is also a difference in relation to the emphasis on who otaku are. Whereas the former work distinguishes otaku from simple fans of anime or manga, as a kind of elite alpha fans, the latter book's approach embraces all fans of the wider otaku sphere of interests from the I980s up until the early 2000 s.

I4. However, Yoshimoto also identifies an otaku specific mode of engagement focusing on community and enjoyment (2009: I 80), as mentioned in the next section related to the divide in Japanese SF culture which occurred in the late I 970 s to early I980s.

I 5. The word moe is commonly understood to denote the affective reaction of readers, viewers and players to fictional characters or to certain character elements. It has become a key term in the discussions around the shift in the focal interests of otaku culture in the late I990s (see Azuma, 2009 [200I]; Maejima 2010; Okada 2008; Uno 2018; Yoshimoto 2009) as will be discussed in later sections in more detail. For a discussion of the possible origins of the term, see Morikawa (2003: 3I). 
I6. For an exploration of the connection between participatory fan practices, imaginary culture and the aesthetic principles underpinning otaku culture, see Kacsuk (20I6a; 20I6b).

I7. See also Chapter 4 by Minori Ishida. otaku culture, it was in fact originally its preferred form. In Otakugaku nyümon, Okada even cites the visual refinedness of otaku in relation to anime viewing as one of their distinguishing features (I996: IO-27). But even more importantly, it is within anime that otaku culture first coalesces into a new recognizable configuration. Furthermore, anime plays a huge role in catalyzing the differentiation of otaku culture from the narrower SF fandom and its spread to a wider public (Yoshimoto 2009; see also Ōtsuka 2004).

In Otaku no kigen (The origin of otaku), Yoshimoto offers a detailed reconstruction of the key events and actors that led to the qualitative change in SF fandom and facilitated the emergence of otaku culture. "Imaginary culture" is the unifying theme for Yoshimoto interconnecting SF, kaijū or special effects works, manga, the occult and anime. SF fandom originally was a very serious affair which required much reading, often even in foreign languages, and an interest in science. In part influenced by US fan practices, a different and more popular way of enjoying SF emerged. It was motivated by participation, in both senses of the word: stepping into the world of the fantastic and taking part in events. These two ways of SF engagement lived alongside each other in a tenuous relationship, but ultimately it was this latter more popular form of enjoyment that led to the emergence of otaku culture (Yoshimoto 2009: I44-167). ${ }^{16}$

Yoshimoto also explains the role played by anime magazines in creating both the critical discourse needed to normalize the shifting of anime from a children-only form to being enjoyable by teenagers and adults, and a country-wide audience connected by this shared space of information and interaction (2009: I 27-I36). ${ }^{17}$ Ōtsuka also emphasizes the importance of anime magazines as a ground where the first generation of otaku working in various writing and editing roles set the tone for anime criticism (2004: I06). Furthermore, these magazines were key in drawing animators into creating manga, the 
most famous example being Hayao Miyazaki's Nausicaä of the Valley of the Wind (Ōtsuka 2004: I08).

\section{The DAICON III opening animation}

In the late 1970 s and early 1980 s, the most important convention that would bring a large number of participants from the various interest groups (SF, manga, anime, kaijū, etc.) together in Japan was the annual SF convention. In 1981, a group of young enthusiasts from Osaka-including Takami Akai, Hideaki Anno, Toshio Okada, Yasuhiro Takeda and Hiroyuki Yamaga - had the opportunity to host the 20th annual SF convention. It was the third time it was held in the city, thus the event was called DAICON III. The name is a word play on daikon radish, and is a portmanteau of the Sino-Japanese reading (on'yomi) of the first character of Osaka (dai) and 'con' from the English word convention (a testament to the influence of US SF fandom). The then art students Akai, Anno and Yamaga worked on the convention's opening animation. It was an inspired work produced via dedication rather than a budget-it was famously created on industrial celluloid as opposed to the more expensive and finer material used for animation - and it was not only outstanding as an amateur piece, but also showcased the many interests of what would become otaku culture. The roughly five-and-a-half-minute short piece shows the fighting-filled journey of a small girl who is entrusted with a glass of water by members of the Science Patrol from Ultraman, which she successfully delivers to water a dismal-looking radish in the ground. On the way, she is confronted with various kaijü, anime and SF-related adversaries, ranging from a Starship Troopers mecha through Godzilla to even a Star Wars star destroyer, with a host of references to further works sprinkled in for good measure. Upon being watered, the radish turns into a huge radish-shaped spaceship called the DAICON III, which the girl boards as its captain to fly off.

Animec (1978-87) was the flagship magazine where many of the intellectual foundations for anime criticism were being laid down, and it was here that the famous "Is Gundam SF?" debate took place, a portent of the growing divide between SF and anime fans (or fans of literary SF and visual SF) (Yoshimoto 2009: I 27-I28). It was also 
I8. The DAICON III opening animation already cites both Western and Japanese works; however, the number of references truly moves to the scale of enumeration in the DAICON IV opening animation, to the point of including a panorama-like tableau of characters. around I980 that the self-evidence of SF literature, manga and anime consumption going together started to break down, in part as a result of the increased supply in works in all of these forms, but also because of a steadily growing audience (2009: I 28-I29).

Not only does anime play a key role in setting the stage for the fully formed crystallization of otaku culture in the early I980s, but the first major formulations of what the 'otaku genre' encapsulates also took the form of anime, the first of which was the manifesto-like DAICON III convention opening animation (I98I) by a group of creators who would later become known as Studio GAINAX (see text box). In 1982, the start of the original broadcast of Super Dimension Fortress Macross followed, also created by a very young team, but reaching a far wider audience. This series showcased SF, idol culture, love comedy, mecha, bishōjo and many more elements boys interested in "imaginary culture" were excited about at the time (Yoshimoto 2009: I65-I66). The DAICON IV opening animation in I983 was already a self-affirming celebration of the otaku mode of engagement. It featured a short summary remake of the DAICON III opening animation, to then welcome back the protagonist as a grown-up woman in a playboy bunny dress fighting and surfing-on Elric's Stormbringer no less-her way through a breathtaking vista of the various interests and stylistic elements that made up otaku culture (including, for example, the highly intricate projectile patterns referred to as "Itano circus" after its animator, Ichirō Itano). ${ }^{18}$ This was followed in 1984 by the release of the movies Nausica $\ddot{a}$ of the Valley of the Wind, Urusei Yatsura 2: Beautiful Dreamer and The Super Dimension Fortress Macross: Do You Remember Love?, which marked the completion of the crystallization of the otaku genre in Yoshimoto's view (2009: I 85-187).

Even though the DAICON III and DAICON IV opening animations were only shown at the corresponding two conventions and later made available on video, the force that would become GAINAX 
is so central to the formation of otaku culture in a practical, discursive and symbolic sense that Yoshimoto regards them as the most important catalysts (2009: I7I). While this premier position in the narrative is no accident, it is not inevitable either. In the last section of this chapter, I will point to potential alternative versions of the history of otaku culture where the centrality of GAINAX is supplanted by other studios.

\section{Defining Anime Booms}

One of the most obvious concepts mobilized with regard to the epoch-making status of EVA is that of anime booms, or more specifically the very boom it engendered. In order to better interrogate the relationship between epoch-making anime and anime booms, let us first reverse the inquiry into whether all epoch-making anime also give rise to anime booms. Astro Boy (1963-66), Space Battleship Yamato (I974-75) and Mobile Suit Gundam (I979-80) are all considered epoch-making anime. Astro Boy was the pioneering work that set the template of limited animation for the whole lineage of TV anime to follow, Space Battleship Yamato opened anime up to a teenage and young adult audience (Yoshimoto 2009) and Mobile Suit Gundam is commonly understood as inaugurating the Real Robot genre (Uno 2018). Remarkably, two out of three of these anime, Space Battleship Yamato and Mobile Suit Gundam, are directly linked to the emergence of otaku culture.

But what actually constitutes an anime boom? The animation historian Nobuyuki Tsugata explicitly reflects on the way in which anime boom is a popular expression that has no set definition, and the meaning of which can vary based on the speaker, especially between generations (2005: I 80). Nevertheless, the impact of this concept is so strongly felt that he too cannot avoid using it, and thus attempts to provide a working definition. In his view, it is not only a quantitative aspect of having a larger number of anime produced (which in itself 
would raise important questions regarding what increase would be large enough to constitute a boom), but also a qualitative shift (as hard to pin down as this criterion might be) in the production, distribution and consumption practices of anime (2005: I 8I). As much as Tsugata tries to reposition the concept as something that can be made sense of within animation research, it is quite telling that the three booms he discusses conform almost completely to the narrative that understands the major turning points within Japanese animation in relation to the development of TV anime and otaku culture. The first anime boom in his interpretation is sparked by the premier of Astro Boy, the second anime boom is initiated by Space Battleship Yamato and the third is characterized by the emergence of a strong overseas interest, represented by the international success of Hayao Miyazaki's Princess Mononoke (1997) (Tsugata 2005: I8I-I82)-this is the point where Tsugata truly broadens the scope of the discussion of anime booms beyond just TV anime and otaku culture. However, a few pages later, he conforms to the common notion that the third boom is actually spearheaded by EVA (2005: I 85 ).

Tsugata's discussion of anime booms shows awareness of the problematic nature of the term, but it also indicates the way in which the concept of anime boom has been intertwined with the lineage of limited animation that finds its most influential manifestation in otaku culture (see Lamarre 2009). Even though Tsugata considers the whole field of Japanese animation, including Astro Boy and Miyazaki, he still cannot forego reinserting EVA into his discussion if only in a side note.

Uno's lectures at Kyoto Seika University (2018) foreground the importance of anime for otaku culture and the role of otaku as instigators of anime booms even more. Uno cites Space Battleship Yamatoinstead of Astro Boy—as the source of the first anime boom, and he names Mobile Suit Gundam the catalyst for the second anime boom, which he explains is easy to miss, since this boom can be seen as a continuation of the one started by Space Battleship Yamato. Why then does he highlight Gundam? As already mentioned, seemingly 
objective economic arguments are often underpinned by far softer, for example, aesthetic and genre-related arguments. Gundam is central to Uno's argument because it was epoch-making from a genre perspective, as the origin point of Real Robot anime. In this regard, it makes sense to position it as the instigating event of an anime boom. But this positioning itself can also be seen as a telltale sign that epoch-making anime and anime boom are potentially co-constituted concepts. Thus, all the epoch-making anime with which I started this section are, of course, also responsible for anime booms, which renders my initial question of whether all epoch-making anime are also responsible for anime booms tautological.

EVA is positioned by Uno as the source of the third anime boom (20I 8). Although this might just be a coincidence and would require further substantiation, it is curious that EVA seems to occupy a set position in the sequence of anime booms. The common understanding that EVA sparked off the third anime boom is apparently so entrenched as to require a narration of anime booms that substantiates its occupation of this position.

\section{Otaku Generations}

The idea of otaku generations was introduced by Okada (I996: 37-39, 48-49). In his formulation, each generation has their point of entry or "home position" (a term borrowed from computer terminology) in otaku culture. For first-generation otaku, born in the decade I955-64, these were special effects series, most notably Ultraman and Kamen Rider. Anime was the most important entry point for second-generation otaku, born between 1965 and I974, especially Space Battleship Yamato and Gundam. The third generation of otaku-born in the Showwa 5 os (1975-84)-have models, Gunpla (Gundam plastic model kits by Bandai), and video games as their distinguishing generational imprints. And, finally, for the then still children, born from I985 onwards, this "home position" is/will be video games. Okada is quick to point out that 
I9. This part of the book is also available in English translation (Okada 2015 [2008]). otaku of all generations irrespective of their "home positions" go on to find the related areas and start crossing over and enjoying a variety of formats and genres. Thus, although the entry point for each generation may differ, the consumed media and genres significantly overlap.

Okada's book contains drawn diagrams of typical room interiors for the first three generations of otaku highlighting the various artifacts of interest with small written captions. The third-generation room includes an EVA poster. Although the book was published in I996, this picture anticipates later references to the third otaku generation that often rely on the generational impact of EVA.

For example, in Otaku: Japan's Database Animals (2009 [200I]), Azuma clearly builds on Okada's idea of otaku generations, but modifies it, regarding the exposure to EVA as emblematic of the third generation.

The first generation centers on those who were born around I960 and saw Space Battleship Yamato ... and Mobile Suit Gundam ... during their teen years. The second generation is made up of those who were born around I970 and, during their teens, enjoyed the diversified and matured otaku culture produced by the preceding generation. The third generation consists of those who were born around I980 and were junior high school students at the time of the Neon Genesis Evangelion boom. (Azuma 2009 [200I]: 6-7)

Maejima, who introduces himself as a model third-generation otaku, that is, a dedicated viewer of EVA in his teens, provides a version of the generational model that merges Azuma's variation into Okada's, with the first two generations mirroring the latter, but the third being fundamentally affected by EVA, voice actors and video games (20I0: 52). In both Azuma's and Maejima's accounts, EVA clearly moved to the forefront of defining third-generation otaku.

Okada revisits his idea of otaku generations in Otaku wa sude ni shinde iru (Otaku are already dead) (2008: 7I-8I). ${ }^{19}$ There, he provides a different angle on what constitutes the main difference between the generations and slightly alters their age range. According to his 
new scheme, first-generation otaku grew up with the TV and were into anime, manga and SF, but did not stand out and just didn't conform to mainstream expectations without much fanfare or backlash. Second-generation otaku, on the other hand, had to bear the brunt of the moral panic following the Miyazaki serial murder case and were consequently most interested in theories about otaku; furthermore, they were the ones who experienced "EVA shock" when the series first aired. The third generation of otaku grew up in an environment already saturated with concurrently available media mixes, thus lacking the experience of the evolution of different contents in anime, manga and games. The various elements of a media mix are almost interchangeable for them, with little or no attention paid to the sequence of original, adaptations, etc. Thus, they pay more attention to the impact of a certain work on themselves than to information on creators. In sum, Okada now suggests a development from firstgeneration hermit hobbyists through the second generation for whom otaku identity posed a central problem to the pure consumers of the third generation.

Okada's new model shifts the defining position of EVA back to the second generation and makes EVA less central than in Azuma's and Maejima's take, while conforming to the ideas introduced by Azuma in relation to the consumption practices of the third generation, which are the subject of the next section on sekaikei. So far, we have seen how closely the concepts of anime boom and otaku generations are related to the significance of EVA. With sekaikei, the concept most heavily indebted to and animated by EVA comes into view.

\section{EVA and Sekaikei}

In many ways, this chapter could be read as a lengthy footnote to Maejima's book Sekaikei to wa nani ka: Posuto eva no otakushi (What Is Sekaikei? A Post-EVA Otaku History, 2010). Sekaikei is a genre label that emerged in the late I990s and continued to enjoy 
prominence during the 2000 s denoting a certain set of works mostly tied to otaku culture. The vagueness of its denotative meaning is precisely why Maejima embarks on the journey to uncover how the term came about and what it connotes.

Today, the most common use of sekaikei concerns works that revolve around ( $\mathrm{I}$ ) a (potentially) romantic relationship between a heroine cast in an active (often fighting) role and a passive male protagonist, whose relationship is (2) somehow tied to a much larger conflict that determines the fate of the world or at least that of the protagonists, (3) with major parts of the world or setting remaining unexplained or even unrepresented. This definition, however, is a later development that resulted in part from Azuma's work on the topic (Maejima 20IO: I40-I48). The fact that the meaning of the term went through such change is a testament to both Azuma's impact on the general discourse around otaku culture and the original vagueness of the term.

Tracing the term sekaikei back to its initial appearance, Maejima cites the website Purunie's Bookmarks, where it meant "EVA-like" in the sense of an intense first-person narrative (2010: I24-I27). He is quick to point out that such an equation of EVA-ness is not exhaustive, since this aspect becomes prevalent only during the second half of the anime series. In fact, he argues, EVA can be seen as having two distinct halves that correspond to the past and future of otaku culture.

According to Maejima's analysis, the first half of EVA is first and foremost a well-made anime both regarding the story and the quality of the animation, and, second, it lays the groundwork for (or looking back from the ending, teases its audience with) a possibly huge and complex world setting and backstory, and, finally, it also references many earlier SF, kaijū and anime works (2010: 37-39). All this adds up to sensibilities that correspond to Okada's early definition of otaku, namely advanced visual refinedness-the opening at the time was especially pushed regarding the rate of cuts and the amount of 
visual information all crammed into it-and interest in tracing references and allusions (2010: 37-39). But the second half of the series departs from the expectations set up initially. First, both the story and the animation become highly experimental in the final two episodes. Second, the focus shifts from the world or setting to the inner self. Third, and most disconcerting of all, instead of affirming otaku dispositions and practices, a self-reflexivity comes to the fore that borders on explicit criticism (see below).

The two halves further correspond to different generations, foci and genre/thematic elements. Whereas the first half exhibits sensibilities of the first and second generation of otaku, a focus on "narrative consumption" (Ōtsuka 2010 [1989]) and an interest in SF, kaijü, Super Robot and Real Robot works, the second half is geared toward the third generation, built around "database consumption" (Azuma 2009 [200I]) and a focus on the story; as such, it is a forerunner of sekaikei and moe moving to the fore of otaku culture (Maejima 20I0).20

In this way, Maejima reiterates and further fleshes out Azuma's arguments. In line with moe becoming the main mode of engagement with otaku creations, and bishōjo characters becoming the emblematic element of otaku works, a shift occurred in the meaning of otaku. ${ }^{21}$ This change in focus coincides with the shift from "narrative consumption" to "database consumption" and a corresponding resurgence of interest in the story as opposed to the world or setting. Finally, EVA signals the end of anime being the central medium of otaku culture.

As mentioned earlier, anime had been central to the formation of otaku culture. Maejima explicitly references Okada's argument about the highly developed visual refinedness of otaku toward moving images and poses the question why then otaku shift their center of attention to still images (visual novels) and written text (in both light novels and visual novels). According to him, moe as an affective response and the turn toward the inner self in the second half of EVA
20. For a more detailed discussion, see Olga Kopylova's Chapter 8.

2I. This is why Okada (2008) as well as other older otaku began to promote a return to the formerly used expression 'mania,' which denotes someone characterized by an intense preoccupation with a particular field of interest like anime, manga, special effects series, trains, etc. 
both find a better terrain of expression in written text (2010: 62-64). In this way, moe and sekaikei stem from a common ground principle, namely, the focus on inner life and emotional states (2010: I I 2).

EVA appears almost prophetic in its unraveling of animation, heralding the shift toward script. The increasing density of intertitles in episodes 25 and 26 seems to signal the strains in depicting the complexity of inner emotional states. Maejima juxtaposes the otaku anime of the first half of the series with what he refers to as "otaku literature" (otaku no bungaku) regarding the second half. Elaborating on this idea helps us to understand the significance of EVA for otaku culture on yet another level.

\section{EVA as "Otaku Literature"}

In How to Read Superhero Comics and Why (2002), Geoff Klock offers a reading of US superhero comics from the second half of the I 980 o into the early 2000 s through the conceptual framework developed by literary critic Harold Bloom (and to a lesser extent Slavoj Žižek's reading of Lacan). Building on Bloom's ideas about the importance of wrestling with the literary tradition, Klock goes on to identify an important point of saturation and rupture in the US superhero comics tradition:

Frank Miller's Batman: The Dark Knight Returns (I986) and Alan Moore's Watchmen (I986) are the first instances of a kind of literature I am going to identify as the revisionary superhero narrative: a superhero text that, in Harold Bloom's words, is a "strong misreading" of its poetic tradition, a comic book whose "meaning" is found in its relationship with another comic book. Although strong work existed in comics before this point-in the works of Will Eisner and Jack Kirby, for example-it is with these titles that, to quote critic Perry Meisel, referring to the blues tradition after swing, "a tradition now [exists] sufficiently dense with precedent to cause the kinds of self-consciousness and anxiety with which we [as students of literature] are familiar." (Klock 2002: 25) 
In Klock's interpretation, these two seminal works effected a rupture in the history of US comics-not unlike the one EVA produced in relation to otaku culture-which can be seen as "the culmination of the silver age" of comics, and which at the same time is the "the birth of self-consciousness in the superhero narrative" (2002: 3). It would be futile to attempt a detailed Bloomian reading of EVA within the space of this chapter, but the impact of EVA on both the works that followed $^{22}$ and the critical discourse around otaku culture mirrors the interventions enacted by Batman: The Dark Knight Returns and Watchmen, and can be seen as a similar point of saturation. In this light, the break described by Maejima between the two halves of EVA can be re-evaluated as less of a break, but rather a realization of what had been unfolding all along. It is the combined picture of the two halves that represents the point of saturation where otaku culture becomes self-reflexive and wrestles with its own influences.

Just as Batman: The Dark Knight Returns and Watchmen explicitly thematize the parallels with fascism and the overt violence and sexual innuendo in superhero comics (the latter also tracing the pulp roots of the genre), so too does EVA offer a critical look at the sexual and power fantasies coursing through so much of otaku culture, while bringing to the fore the kaiju roots at the heart of robot anime. ${ }^{23} E V A$ brings the Real Robot genre back to its Super Robot and kaijū origins by returning to the template of the adversaries (in this case, the Angels, who are also uncannily similar to their kaiju forefathers in their otherworldly and perplexing forms) descending on the protagonists' base as opposed to the action playing out in some outer space theater of war (Maejima 20I0: 82). Nowhere is this connection made more explicit than in the revelation that the Eva units themselves are created from Angels. Thus, the historical development of a whole lineage of interrelated (sub)genres is captured in the allegory of the kaiju body hidden under the surface of the Real Robot exterior. What's more, the gradual unveiling of the connection between the Eva units
22. See Maejima (2010: 56-57).

23. "The giant kaijū monsters, heroes, and machines that rose to popularity with mid-I96os tokusatsu shows formed the 'soil' from which robot anime would bloom so vibrantly in the I970s. Robot anime did not develop in a vacuum as an independent, isolated creation of the animation industry" (Hikawa 20I3: I 2). 
24. See Uno (2018) for the significance of the occult in otaku culture; also Yoshimoto (2009).

25. The DAICON III opening animation from I98I was a huge hit, and thanks to the business sense of Okada, its direct video sales to fans greatly contributed to raising the financial resources for the future ventures of the group that would eventually become GAINAX in I984. Following DAICON III, they created various live-action short films, parodies of special effects series like Ultraman and Go Rangers, under the name DAICON FILM. In I982, Okada and Yasuhiro Takeda formed the company GENERAL PRODUCTS to deal in custom hobby model kits, T-shirts and other fan-made merchandise. This was seen by many as an attempt to make money off the back of the SF fan culture and led to a certain level of backlash within the fandom (Yoshimoto 2009: I 55 ).

26. See Uno's citing of Shūichirō Sarashina's summary that sekaikei is basically the version of EVA where Asuka does not reject Shinji (201 8: 274).

27. I have not touched on the question of otaku sexuality, which is an import branch of the discussion around the term otaku. For more on the topic, see Saitō (20I I [2000]), Ōtsuka (2004), Morikawa (2003) and Galbraith (2015). and the Angels corresponds to the way in which the two halves of $E V A$, as described by Maejima, are actually linked by the move from the visible exterior trappings to the underlying themes and veins of influence of otaku culture.

Considering that EVA was produced by GAINAX, we can see how it reiterates the deep engagement with otaku culture on a meta-level that had been the hallmark of this group of creators from the very beginning. EVA is a grand synthesis of the many components of otaku culture from kaiju to robot anime, SF and the occult ${ }^{24}$ in the vein of the DAICON III and IV opening animations, and at the same time, it is a critical commentary on otaku culture itself, not unlike the selfreflexivity found in the I99 I part-anime, part-mockumentary Otaku no video, which relates the heroic tale of two otaku creating the ultimate otaku business empire (a commentary on GENERAL PRODUCTS ${ }^{25}$ and potentially also GAINAX), interspersed with live mock footage of interviews with various types of otaku.

Even though on the surface the ending offered in the feature film End of Evangelion might seem to be moving away from the breakdown of animation and the complete focus on Shinji's inner life in the series' finale, the turn toward interiority is not loosened; it becomes even more brutal, in Maejima's view, with Asuka's rejection of Shinji as disgusting (2010: 45-47). ${ }^{26}$ Instead of an "extremely otaku-oriented anime," it becomes "otaku literature," and the story of otaku maturing while fighting using a giant robot is replaced with the figure of an otaku masturbating to a bishōjo (2010: $46-47$ ).27

Both sides of this last point are closely connected to Ōtsuka's reading of the significance of EVA in "Otaku" no seishinshi: I98onendairon (A Mental History of "Otaku": About the I980s) (2004). As already mentioned in the introduction, Ōtsuka was one of the vocal critics of the series following its original run. Less than ro years later, he explicitly re-evaluates his stance and aligns his reading of the work to the landmark status it occupies within the Japanese critical discourse. His 
argument is premised on the lack of rites of passage in modern societies and he relates this to the way youth, and otaku especially, refuse to grow up and to conform to social expectations (2004: 40I). In this, Ōtsuka finds a direct connection to "Astro Boy's dilemma" (Atomu no meidai). In his book of the same title (2003), Ōtsuka maintains that many developments in post-war manga have been propelled by the inherent tension between the cartoon body and a deeper 'literary' self bestowed on the drawn figure. One aspect of this tension is the inability of cartoon characters to age and grow, and while this is not specific to Japanese manga, Ōtsuka finds it interesting that this trait comes to the fore in a number of Tezuka's protagonists, who are trapped in bodies that are both metaphors for and direct causes of their arrested development, starting with Astro Boy's childlike robot body (2004: 402). He sees many of the defining works in post-war Japanese manga (and anime) as stories of failed attempts at a proper bildungsroman (or coming-of-age story) (2004: 402-404). This prevalence of the motif of arrested development in both characters and narratives in post-war Japanese manga, in Ōtsuka's view, is not unrelated to the position Japan occupied vis-à-vis the United States following World War II, most emblematically expressed in the way General Douglas MacArthur had likened the Japanese people to a I 2 -year-old boy. For Otsuka, EVA is a significant work because it is the ultimate form of addressing Astro Boy's dilemma. He likens the congratulatory scene at the very end of the anime series to a self-realization seminar ${ }^{28}$ and points out that this is the only possible substitute for a rite of passage in late modernity as there are no communities left into which one could enter as an adult. Thus, the series' ending elides Astro Boy's dilemma-neither fulfilling the need for a rite of passage nor postponing it indefinitely - and at the same time, while commenting on it, renders it void (2004: 405-406).

Curiously enough, Ōtsuka reads End of Evangelion as an even more radical engagement with Astro Boy's dilemma. The movie's ending
28. Uno makes a direct connection between Ōtsuka's self-realization seminar interpretation and Aum Shinrikyō's focus on changing the self (2018: 259-260). On this note, the Human Instrumentality Project and Shinji's rejection of it could also be read as a critique of Aum Shinrikyō. 
turns toward an unflinching affirmation of the unfulfilled bildungsroman. As a result of Shinji trying to choke Asuka, the possibility of identifying with Shinji is negated, and thus the point of identification is moved to Asuka, where it is promptly denied once again (2004: 407-409). For Ôtsuka, this final scene, where the viewers are condemned from the viewpoint of the girl victims, is the first case in otaku culture to address the Miyazaki murders (2004: 4IO-4II).

With its radical formulations of the impossibility of the bildungsroman, EVA comes to symbolize the end point of postwar manga and anime history for Ôtsuka. The way it formulates this impossibility is precisely why it cannot be processed within otaku culture, why otaku enthusiastically (re)turn to Gundam as if EVA had never happened, and why so much of EVA merchandise is based on the alternate sliceof-life school setting version of the characters from the series finale (2004: 4II).

Consequently, approaching EVA as the begining of "otaku literature," that is, a saturation point where otaku culture becomes selfreflexive, not only helps align Maejima's and Ōtsuka's arguments, but also underscores EVA's unique position in the discourse around otaku culture. Even Ōtsuka finds a way to conform to it. A similar transformation can be seen in Uno's writing, but is almost immediately undone by himself, as I will proceed to demonstrate.

\section{Imagining Alternative Versions of the Critical Discourse on Otaku Culture}

In Zero nendai no sōzōryoku (The Imagination of the Millenial Generation), Uno discussed EVA from a point of view that attempts to encompass the development of Japanese popular culture in general, analyzing not just anime and manga, but also television dramas, movies and novels. Furthermore, he tried to create a counter-narrative to Azuma's interpretation, which had become dominant within the critical discourse. One of his key ideas revolved around the change 
of imagination from the hikikomorism/psychologism of the midI990s, ${ }^{29}$ represented by EVA, to so-called determinationism ${ }^{30}$ (ketsudanshugi). Hikikomorism was characterized by a fear of hurting others and, as a result, refraining from action (exemplified by Shinji's refusal to pilot his Eva unit), as well as a desire to be nevertheless accepted as is. Determinationism, on the other hand, entailed the realization that even refraining from action is a form of action, and there is no escaping the necessity to act, if one doesn't want to be left behind or killed. This threat is particularly pronounced in the first wave of determinationism works that Uno calls battle royal both as a gesture toward the Hobbesian struggle of all versus all, and as a reference to the book Battle Royal (1999). In his view, sekaikei works are just a belated and debased form of hikikomorism/psychologism. This devaluation of post-EVA sekaikei works can be seen as a denigration of the significance of EVA, even if the series itself is invoked as the single best representative of hikikomorism/psychologism, and it can arguably make sense from the vantage point of surveying Japanese popular culture in general, as opposed to focusing only on anime and otaku culture.

In comparison, in Wakai dokusha no tame no sabukaruchāron kōgiroku (Subculture Theory for Young Readers, Lecture Recordings), Uno concentrates on otaku culture only, and as such yields to the power of the discourse surrounding EVA, referring to it as the "final accounts" of the robot anime genre (2018: 195) and positioning it as the landmark work that it is assumed to be. This, however, is only a concession to the power of the critical discourse around EVA.

Uno offers a detailed reading of a large number of important robot anime in this book, pointing out at the very start that most of the famous robots after Astro Boy, like Tetsujin 28-gō (or Gigantor), Mazinger Z, Gundam and the Evangelions, are not intelligent beings, but tools (Tetsujin 28-gō is remote-controlled) or vehicles (201 8: I40). All are created by a father figure, and after Astro Boy they are all devices of fulfilling the dream of young boys to become men (2018: I99).
29. Hikikomori is the Japanese term for people withdrawing to an extreme degree from face-to-face social interactions (e.g., shutting themselves in).

30. I am following Suan (2018: 233) with this translation, meant to convey the sense of being determined to make a choice and take action. 
The robot as vehicle in particular enables the young boy to partake in adult affairs by donning a larger-than-life body. They are further products of industrial mass production (as opposed to the previous quasi-magical and unique super robots like Mazinger Z) starting with Gundam, which moves robot anime into full alignment with modern society and thus the problems of teenagers of the time (2018: I99).

Although the first Gundam series offered the vista of potential self-realization in a fictional war-torn world, the latter series in the franchise, like Mobile Suit Zeta Gundam, provide increasingly grim images of what this self-realization entails, such as going mad, or dying young without ever becoming men, as depicted in Mobile Suit Gundam: Char's Counterattack (Uno 201 8: 200). In this way, the Gundam series signals the limits of the type of masculinity that can be manifested in a militarized industrial society (ibid.). Finally, in the I990s, EVA goes on to destroy the robot anime lineage completely by finding its closure in a "self-realization seminar" (ibid.).

This all seems like a sound line of argument, but Uno himself in the very same book unhinges the underpinnings of his take on EVA as the "final accounts" of the robot anime genre. In a latter chapter, he describes in detail how the Mobile Suit Victory Gundam series, which already aired in 1993-94 and is thus a precursor to EVA, negates all possible positive identification with any of its adult male characters. According to his interpretation, it is an outright declaration of the impossibility of believing in the promise of post-war robot anime about growing up in a fictional space century by getting hold of a giant robot body (2018: 279). He even claims that EVA does not go as far as Victory Gundam in its demolition of the robot anime lineage. But if this is the case, then Uno's previous statement about EVA's position in the lineage of robot anime does not hold; it turns out to be a concession to the consensus that has come to dominate the critical discourse.

As a quick thought experiment, let's imagine a version of Uno's book in which he does not go along with the common understanding 
of EVA. What if the story of otaku culture were told through a different perspective? One in which EVA is no more significant than, for example, Gunbuster (I988-89), the hit OVA series from GAINAX that foreshadowed certain elements of EVA. The level of detail with which Uno examines the different Gundam series stands in sharp contrast to the usual lack of attention afforded to Gundam in the publications considered so far. In fact, Uno's discussion of Gundam and the role of the creator/director behind the series, Yoshiyuki Tomino, as a pioneer of various themes for which EVA is celebrated, provide all the necessary ingredients for a well-formed alternative narrative of otaku culture. This narrative would see a lineage of otaku culture running from Osamu Tezuka in a more tightly coupled fashion $^{31}$ via his animation studio Mushi Production leading to the establishment of Sunrise Studio by former members of Mushi Pro in 1972. The emergence of Gunpla would figure as pivotal in the development of custom hobby model sales and the otaku market in general. Finally, in this version, the meaning of otaku culture would probably be more closely aligned with Okada's understanding of otaku as mania (first and second generation otaku), and moe-centered otaku culture might be regarded as a new formation altogether, similar to how otaku culture initially branched off from SF fandom. This potential for different versions of the narrative ${ }^{32}$ evinces just how central EVA has been within the critical discourse around otaku culture.

\section{Conclusion}

EVA's position as an epoch-making anime is often taken for granted, as are the apparently objective arguments in relation to its economic impacts, but I hope to have demonstrated that there are layers upon layers of deeper connections between EVA's position as a landmark work and the way in which otaku culture is addressed in the Japanese critical discourse.
3I. See also Yoshimoto (2009).

32. Another possible axis of re-imagining this narrative would revolve around Studio Nue and the Macross series (I am grateful to Luca Bruno for pointing this out) and highlight the centrality of idol culture to otaku culture; which is surprisingly very much in line with Uno's assessment of the development of otaku culture following the 20II Tohoku earthquake and tsunami, where idol culture moved to the fore in his view. $\mathrm{He}$ even points out the uncanny parallels to Macross in $\mathrm{AKB}_{4} 8$ 's visits to the disaster struck areas (2OI8: 3OI-302). 
First, EVA has left its imprint on a number of concepts and terms that are mobilized whenever its significance is at stake, namely anime booms, otaku generations and sekaikei. The series seems to occupy a set position in the enumeration of anime booms as spearheading the third boom. Otaku generations are often conceptualized in a way that one of the generations is defined by the EVA shock of the second half of the I990s. And sekaikei is a testament to the power of EVA, providing a jumping-off point for both the proliferation and the interpretation of a whole group of related works.

Second, the weight of the consensus around EVA's position forces even previously dissenting voices to incorporate its landmark status into their interpretations. For Ōtsuka, EVA has come to symbolize the ultimate engagement with Astro Boy's dilemma, and thus the culmination point of postwar Japanese manga and anime history. On the other hand, Uno, while also espousing EVA as the "final accounts" of the robot anime genre, actually provides the blueprint for an alternative retelling of the history of otaku culture, one that would revolve around Gundam, which again accentuates the force of the consensus around the centrality of EVA in otaku culture.

Third, the position enjoyed by EVA can be further substantiated by considering EVA as a saturation point where otaku culture becomes self-reflexive and, as Maejima writes, turns into "otaku literature." The impact of EVA on the anime industry and otaku culture mirrors the intervention effected by Batman: The Dark Knight Returns and Watchmen in American superhero comics, as described by Klock.

Furthermore, I also want to draw attention to the fact that, in the present chapter, I perpetuated the very same operations I have been analyzing. While highlighting the way in which EVA's landmark position has been established in the Japanese critical discourse and has become seemingly inseparable from the manner in which otaku culture is understood, I too have added another layer of arguments that work toward further cementing and naturalizing its position as an epoch-making anime. 
Finally, I hope that the present discussion has also managed to highlight just how strongly the development of anime and otaku culture are intertwined, from the significance of anime as the focal point for the crystallization of otaku culture to the impact that first generation otaku had on shaping anime criticism as well as the industry itself, with GAINAX being the premier example. Although my focus has been on the Japanese critical discourse around EVA and otaku culture, the points of connection between anime and otaku culture go far deeper than the web of concepts and arguments employed within the discussions around these two topics. Indeed, reading the works of Azuma (2009 [200I]), Maejima (2010), Morikawa (2003), Okada (I996), Ōtsuka (2004), Uno (2018) and Yoshimoto (2009) among others on otaku culture provides a wealth of insights into the way so many of the defining creators, major works, genres, formats and audiences of anime, as well as the production, dissemination and consumption practices around anime and its media coverage have all both impacted and have been influenced by otaku culture. Thus, one could say that no serious scholar of anime can neglect to engage with otaku culture, just as no comprehensive work on otaku culture can be written without the necessary foundations in research on anime.

\section{References}

Aida, M. (20I5). The Construction of Discourses on Otaku: The History of Subcultures from I983 to 2005 (translation by Thiam Huat Kam). In P. W. Galbraith, T. H. Kam and B.-O. Kamm (eds.), Debating Otaku in Contemporary Japan: Historical Perspectives and New Horizons (pp. I05-I 28). London: Bloomsbury.

Azuma, H. (2009). Otaku: Japan's Database Animals. Minneapolis, MN: University of Minnesota Press. (Introduction and translation by J. E. Abel and S. Kono)

Beaty, B. \& Woo, B. (2016). The Greatest Comic Book of All Time: Symbolic Capital and the Field of American Comic Books. New York: Palgrave. 
Becker, H. S. (1982). Art Worlds. London: University of California Press.

Bourdieu, P. (1996) [1992]. The Rules of Art: Genesis and Structure of the Literary Field. Stanford, CA: Stanford University Press.

Eng, L. (2OI2). Anime and Manga Fandom as Networked Culture. In M. Ito, D. Okabe and I. Tsuji (eds.), Fandom Unbound: Otaku Culture in a Connected World (pp. I 58-178). London: Yale University Press.

Galbraith, P. W. (201 5). “'Otaku' Research” and Anxiety about Failed Men. In P. W. Galbraith, T. H. Kam and B.-O. Kamm (eds.), Debating Otaku in Contemporary Japan: Historical Perspectives and New Horizons (pp. 2I-34). London: Bloomsbury.

, T. H. Kam and B.-O. Kamm (2OI 5 ). Introduction: "Otaku" Research: Past, Present and Future. In ibid. (eds.), Debating Otaku in Contemporary Japan: Historical Perspectives and New Horizons (pp. I-I 8). London: Bloomsbury.

Hikawa, R. (ed.) (2013). Japanese Animation Guide: The History of Robot Anime. Tokyo: Mori Building Company, Ltd. https://mediag .bunka.go.jp/projects/project/images/JapaneseAnimationGuide.pdf

Itō, G. (2005). Tezuka izu deddo: Hirakareta manga hyōgenron e. Tokyo: NTT Publishing.

Ito, M. (20I2). Introduction. In M. Ito, D. Okabe and I. Tsuji (eds.), Fandom Unbound: Otaku Culture in a Connected World (pp. xi-xxxi). London: Yale University Press.

Kacsuk, Z. (2016a). From "Game-Like Realism" to the "Imagination Oriented Aesthetic": Reconsidering Bourdieu's Contribution to Fan Studies in the Light of Japanese Manga and Otaku Theory. Kritika Kultura, 26, 274-292. (2016b). From Geek to Otaku Culture and Back Again: The Role of Subcultural Clusters in the International Dissemination of Anime-Manga Culture as Seen through Hungarian Producers. Doctoral dissertation. Kyoto Seika University.

Kamm, B.-O. (2015). Opening the Black Box of the 1989 Otaku Discourse. In P. W. Galbraith, T. H. Kam and B.-O. Kamm (eds.), Debating Otaku in Contemporary Japan: Historical Perspectives and New Horizons (pp. 5 I-70). London: Bloomsbury. 
Kikuchi, S. (2015). The Transformation and the Diffusion of "Otaku" Stereotypes and the Establishment of "Akihabara" as a Place-Brand (translated by K. Nishimura and B.-O. Kamm). In P. W. Galbraith, T. H. Kam and B.-O. Kamm (eds.), Debating Otaku in Contemporary Japan: Historical Perspectives and New Horizons (pp. I47-I6I). London: Bloomsbury.

Klock, G. (2002). How to Read Superhero Comics and Why. New York: Continuum.

Korzybski, A. (1996) [1933]. Science and Sanity: An Introduction to Non-Aristotelian Systems and General Semantics. New York: The International Non-Aristotelian Library Publishing Company.

Lamarre, T. (2009). The Anime Machine: A Media Theory of Animation. Minneapolis, MN: University of Minnesota Press.

Leonard, S. (2005). Celebrating Two Decades of Unlawful Progress: Fan Distribution, Proselytization Commons, and the Explosive Growth of Japanese Animation. UCLA Entertainment Law Review, I2(2), I 89-266.

Maejima, S. (2010). Sekaikei to wa nani ka: Posuto EVA no otakushi. Tokyo: Soft Bank Creative.

Malone, P. M. (2010). The Manga Publishing Scene in Europe. In T. Johnson-Woods (ed.), Manga: An Anthology of Global and Cultural Perspectives (pp. 3 I 5-33 I). New York: Continuum International.

Morikawa, K. (2003). Shuto no tanjō: Moeru toshi Akihabara. Tokyo: Gentosha.

. (20I2) [2003]. Otaku and the City: The Rebirth of Akihabara. In M. Ito, D. Okabe and I. Tsuji (eds.), Fandom Unbound: Otaku Culture in a Connected World (pp. I33-I 57). London: Yale University Press.

Okada, T. (I996). Otakugaku nyūmon. Tokyo: Ohta shuppan. . (2008). Otaku wa sude ni shinde iru. Tokyo: Shinchōsha. . (2015) [2008]. The Transition of Otaku and Otaku (translated by B.-O. Kamm, introduction P. W. Galbraith). In P. W. Galbraith, T. H. Kam and B.-O. Kamm (eds.), Debating Otaku in Contemporary Japan: Historical Perspectives and New Horizons (pp. I63-I77). London: Bloomsbury. 
Ōtsuka, E. (2003). Atomu no meidai: Tezuka Osamu to sengo manga no shudai. Tokyo: Tokuma shoten. . (2004). "Otaku” no seishinshi: I980nendairon. Tokyo: Kodansha. . (2010) [1989]. World and Variation: The Reproduction and Consumption of Narrative. (Introduction and translated by M. Steinberg). Mechademia, 5, 99-I 16.

Pellitteri, M. (2010). The Dragon and the Dazzle: Models, Strategies, and Identities of Japanese Imagination: A European Perspective. Latina: Tunué.

Saitō, T. (20I I) [2000]. Beautiful Fighting Girl). Minneapolis, MN: University of Minnesota Press. (Translated by J. K. Vincent and D. Lawson, commentary H. Azuma)

Suan, S. (2018). Anime's Identity: Performativity and Media-Form in Our Moment of Globalization. Doctoral dissertation. Kyoto Seika University.

Thornton, S. (1996) [1995]. Club Cultures: Music, Media and Subcultural Capital. London: Wesleyan University Press, published by University Press of New England.

Tsugata, N. (2005). Animēshongaku no chikara. Tokyo: Heibonsha.

Uno, T. (2008). Zero nendai no sōzōryoku. Tokyo: Hayakawa Shobō. . (2018). Wakai dokusha no tame no sabukaruchāron kōgiroku. Tokyo: Asahi Shimbun Shuppan.

Williams, R. (1979) [1976]. Keywords: A Vocabulary of Culture and Society. Glasgow: Fontana/Croom Helm. . (I980) [1961]. The Long Revolution. Harmondsworth: Penguin Books.

Yamanaka, T. (2015). Birth of "Otaku": Centering on Discourse Dynamics in Manga Burikko (translated by K. Nishimura). In P. W. Galbraith, T. H. Kam and B.-O. Kamm (eds.), Debating Otaku in Contemporary Japan: Historical Perspectives and New Horizons (pp. 35-50). London: Bloomsbury.

Yoshimoto, T. (2009). Otaku no kigen. Tokyo: NTT shuppan. 